\title{
Effectiveness of an Interactive Educational Video on Knowledge, Skill and Satisfaction of Nursing Students
}

Jansirani Natarajan, "Mickael A. Joseph, Zainab S. Al Shibli, Safa S. Al Hajji, Diana K. Al Hanawi, Arwa N. Al Kharusi, Intisar M. Al Maqbali

\begin{abstract}
Objectives: This study aimed to compare the interactive educational video-based strategy with traditional general demonstration in regard to teaching a basic nursing skill. Nursing education requires innovative teaching strategies for teaching fundamental nursing skills to ensure proficient nurses for the future. However, nursing educators face challenges in teaching and retaining the skill competency and knowledge of the nursing students, given shortages of nursing faculty and scarcity of opportunities for clinical practice. Methods: This crosssectional comparative study followed 55 nursing students enrolled in the Fundamentals of Nursing Laboratory course, College of Nursing, Sultan Qaboos University, Muscat, Oman, during the Spring 2020 semester. The control group was taught using traditional general demonstration-based teaching of the oral medication procedure, while the experimental group learned the same skill through an interactive educational video. The knowledge, skill competency and satisfaction levels of both groups were assessed post-intervention using standardised questionnaires. Results: There was no statistical difference between the two groups in knowledge level and skill competency scores. Regarding satisfaction, $92 \%$ of the students were satisfied with video learning and $87 \%$ with the traditional approach. Conclusion: The interactive video learning strategy for learning fundamental nursing skills is as effective as the traditional face-to-face general demonstration-based approach.
\end{abstract}

Keywords: Nursing; Instructional Film and Video; Knowledge; Personal Satisfaction; Education; Teaching; Oman.

\section{AdVANCES IN KNOWLEDGE}

Using an interactive video as a strategy for learning a nursing skill is as effective as the traditional face-to-face general demonstrationbased approach, although further studies are required to confirm this finding.

Interactive videos to learn fundamental nursing skills support learning and promote student achievement and satisfaction.

\section{Applications to Patient Care}

With the spread of COVID-19 still being a threat, using technological strategies such as videos are of utmost importance so nursing students can learn the necessary skills anytime and anywhere.

Watching interactive videos before coming to class allows students to better prepare for the class, thus reducing time for lectures and providing more time for practice and feedback.

Using interactive videos could enhance nursing clinical skills, which are critical for patient care.

Ensuring high levels of competency in learning medication administration skills may reduce medical errors and healthcare costs and enhance patient safety.

$\mathrm{N}$ URSING STUDENTS ARE EQUIPPED WITH basic nursing skills in the Fundamentals of Nursing Laboratory course. These skills are often reviewed during their course of study and their time as nurses in the clinical setting. The quality of patient care and patient safety can be compromised when basic skills are not learned properly and this compromise can even cause permanent disability or endanger patients' lives in severe cases. ${ }^{1}$

General laboratory-based demonstrations of skills are the most common strategies used to teach basic nursing skills to nursing students. The approach involves explaining the procedure, showing students how to perform it step by step and supporting students in practicing the skill to acquire knowledge and competency. ${ }^{2-4}$ However, as new teaching methods are evolving, the approaches to training nursing students also must be upgraded. Technology has made everything easier and faster and is attractive to the millennial generation of nursing students. ${ }^{5}$ One such technology that is gaining greater attention in the educational field is the use of interactive educational videos.

Using interactive educational videos is an innovative teaching approach to teaching fundamental nursing skills to undergraduate nursing students who live their daily lives equipped with highly advanced mobile technology. ${ }^{6}$ Such videos, when used to complement face-to-face education, have been found to improve students' competencies as well as their 
learning. ${ }^{7}$ Nursing educators are encouraged to use various forms of technology to enhance the learning experiences of nursing students, as emphasised in the Vision Statement of the American National League for Nursing. ${ }^{8}$

Educational videos convey information to the learner through aural and visual sensory channels simultaneously, which may result in better learning outcomes. ${ }^{9}$ In addition, videos are more consistent (in terms of the steps used in teaching nursing skills) than demonstrations of skills by different nursing faculty. ${ }^{10}$ Branigan remarked that an increasing number of educators are embracing video as an instructional tool because of the rise in the number of multimediaenabled computers at colleges and the lower cost of video-editing equipment and software. ${ }^{10}$ A growing trend of active usage of social media for networking and communication has also been observed among today's youth. ${ }^{11}$ A systematic review revealed that highly informative educational videos with authoritative speakers that posed questions had a positive impact on the learning interest of students and their selfreported knowledge gains. ${ }^{12}$ Furthermore, students have expressed that educational videos improve their memory of new information and provide better intelligibility. ${ }^{11}$ Videos also provide greater opportunities for students with diverse learning styles to learn at their own pace, for instance, when taught in the context of a flipped classroom-an instructional strategy wherein students listen to the lectures at home and engage in active learning during class time. ${ }^{13}$

Interactive educational videos can increase the learning-related self-confidence and self-motivation of nursing students. ${ }^{14,15}$ Student satisfaction and skill competencies were found to have been improved in a study conducted among Korean nursing students that compared the use of educational video with traditional methods. ${ }^{16}$ Additionally, nursing students' knowledge has been shown to improve when educational videos were used for theory and clinical learning. ${ }^{17}$ Overall, educational videos are considered an adequate teaching approach for students to learn fundamental skills independently and at their own pace.

Nevertheless, despite the numerous advantages of educational videos, nursing faculty and students have been reluctant to adopt this approach because of a misconception that the traditional method of general demonstration results in better student outcomes. ${ }^{18}$ However, the traditional method of teaching nursing skills in a Fundamentals of Nursing course consumes faculty time and other resources. Clinical instructors may need to repeat their explanation many times as students have different levels of understanding. Clinical instructors are also generally restricted to using only a single technique to explain the concept and skill, as they do not have adequate time to deliver the information using multiple methods, which may not ensure the understanding of all students. The use of interactive educational videos can solve most of the problems faced by nursing students and clinical instructors of a Fundamentals of Nursing course, thus saving resources and time.

A review of the literature has revealed a dearth of studies on the use of interactive educational videos for learning fundamental nursing skills in the Middle East. Therefore, this study aimed to compare the knowledge, skill and competency of learning the procedure of administrating oral medication among the fundamentals of nursing students using either an interactive educational video or the traditional general demonstration approach. Moreover, this study sought to describe the satisfaction levels of students with both strategies. The topic was chosen because errors in administering medication are common among nursing students in the clinical setting worldwide. ${ }^{19}$

\section{Methods}

This quantitative study was conducted at the College of Nursing, Sultan Qaboos University, Muscat, Oman, and involved second-year nursing students enrolled in the Fundamentals of Nursing Laboratory course in the Spring 2020 semester. This study used a quantitative comparative design. The college offers the Baccalaureate of Nursing (BSN) and Master of Nursing programmes to students from various parts of Oman. As the college has a multinational faculty, the interactive educational video technology could be beneficial to the new faculty in ensuring uniformity in teaching a skill. Two laboratory groups already existed for this course based on students' enrolment in the course. The authors randomly assigned one of the two $(\mathrm{n}=30)$ as the control group, which then learned medication administration skills using a traditional demonstration method. Students from the other group ( $n=25$ ) were assigned to the experimental group and learned the same procedure by watching an interactive educational video prepared by the faculty. This recruitment meets the requirements of sample size for a study with a 95\% confidence interval for a sample size of 50 participants. Using $G$ power analysis, a sample size of 54 students was needed with the medium effect size of $d=0.5$ and power of 0.70 .

The students in the control group came to the laboratory on two days (Sunday and Monday) of one week for eight hours each day. They were exposed to face-to-face laboratory demonstrations of oral medication administration performed 
by the Fundamentals of Nursing instructor. The demonstration started with a presentation of an overview of medication administration using a Microsoft PowerPoint 2016 (Microsoft Corporation, Redmond, Washington, USA), followed by a face-toface general demonstration in the laboratory by an expert course faculty. The demonstration was followed by the faculty answering the students' questions and clarifying uncertainties. Then, the students performed the procedure in front of their clinical instructors and were evaluated using the procedure checklists.

The experimental group came to the laboratory on two different days from the control group (Wednesday and Thursday) of one week for six hours each day. The students watched an interactive video about the medication administration skill on their own time at home and came to class prepared to perform the procedure. After they had reached the laboratory, an overview of the procedure was presented to the students with the same PowerPoint (Microsoft Corporation) presentation as the control group and their questions were answered for clarification. Then, the students performed the procedure in front of their group clinical instructors and were evaluated using the procedure checklists. After the procedure demonstrations, both groups of students answered a survey on satisfaction using standardised questionnaires.

An interactive educational video is defined as a teaching approach that uses a digital video containing interactions via gestures, voice and touch. ${ }^{20}$ In this study, the interactive educational video was developed based on the nine events of instruction for designing an instructional material as outlined by Gagné. ${ }^{21}$ Gagnés events are: (1) to gain attention; (2) to describe the goal; (3) to stimulate prior knowledge; (4) to present the material to be learned; (5) to provide guidance for learning; (6) to elicit performance; (7) to provide feedback; (8) to assess performance; and (9) to enhance retention and transfer. When video materials match these steps, higher levels of achievement in student learning outcomes and learner engagement can be accomplished.22

The interactive educational video was developed by the experienced course coordinator and uploaded to Moodle, version 3.11.2 (Moodle, Perth, Australia; the learning management system accessed by students), two days before their laboratory session. To ensure consistency, the same faculty performed the face-to-face demonstration and were present in the video. The video was created with the help of the technical support team at the College of Nursing. The video was recorded in the skill laboratory at the College of Nursing, where the faculty performed the administration of oral medications on a trained standardised patient using all the equipment available in the laboratory and following a checklist developed for this course. The video was recorded in one session, which lasted around two hours. In addition, a concise voice narration was recorded to help clarify the demonstration in the video. The technical team used Adobe Premiere Pro (Adobe Stock, San Jose, California, USA) to edit the video and sync it with the voiceover. The video was divided into three parts, each six minutes long. The parts consisted of an overview of medication administration as a recorded PowerPoint (Microsoft Corporation) presentation, a demonstration of the oral medication administration on a standardised patient and a discussion of the aftercare and other policies to be considered while administering oral medications in the clinical setting. The final version of the oral medication video was shared with two professors from the Fundamentals of Nursing course and two clinical instructors to verify the accuracy and the quality of the video, before it was released to the students participating in this study.

A knowledge questionnaire regarding the oral medication administration procedure was developed by the course coordinator based on the National Council Licensure Examination-pattern multiplechoice questions (MCQs) and peer-reviewed by two experts. Five questions were scored, with a score of 5 indicating an excellent level of knowledge, 3-4 a good level of knowledge and 1-2 a poor level of knowledge. The test-retest reliability scores were 0.8 , indicating high reliability.

A performance checklist for an oral medication administration was developed for the objective structured clinical examination (OSCE) by the course team based on the textbook for the Fundamentals of Nursing course and approved by the Department Board. ${ }^{23}$ The mean inter-rater score was 0.9, indicating high reliability.

Satisfaction with the interactive educational videos was measured with the Evaluation of Satisfaction for the Video-Based Interactive Education Method in Professional Skills Training questionnaire developed by Arslan et al. ${ }^{24}$ It comprises 17 items designed to assess every stage of the learning processing, starting with watching the videos. For each item, the participant could choose 1 (disagree), 2 (neutral) or 3 (agree) as their level of satisfaction, with 17 being the minimum and 51 being the maximum possible score. In the study, the total score was converted to a percentage, with a result of $60 \%$ or above indicating a high satisfaction level. Cronbach's alpha was 0.9, indicating very good internal consistency and showing the tool's high reliability. ${ }^{24}$ 
The Student Evaluation of Educational Quality (SEEQ) questionnaire was used to assess the students' satisfaction levels after general demonstration of the skill. It is a five-point Likert scale developed by Coffey and Gibbs ( 5 is strongly agree and 1 is strongly disagree) and consists of 12 items enquiring about the classroom demonstration. ${ }^{25}$ The resulting scores were converted to percentages and a score above $60 \%$ was considered satisfactory. The SEEQ questionnaire has a high level of reliability, with Cronbach's alpha ranging from 0.88 to $0.97 .{ }^{26}$

The control group had general demonstration and hands-on practice of the procedure on the first day. Re-demonstration of the procedure in OSCE was evaluated by two nursing faculty with the help of the checklist after the students had answered the knowledge quiz. Finally, the participants were asked to complete the SEEQ survey to evaluate their satisfaction levels.

The experimental group watched the interactive educational video recording of the oral medication procedure, then came to the laboratory to practice. They completed a knowledge quiz after a brief review of the procedure in the video. The students performed the procedure in the laboratory, which was evaluated by two teams of faculty. The questionnaire regarding satisfaction with the video-based interactive education was completed by the students at the end of the laboratory session, during the scheduled laboratory hours and with the permission of the course coordinators. They could complete it in six hours as they had saved some time otherwise spent on demonstration by watching the interactive educational video.

The collected data were checked for completeness, and scores were calculated and entered by two investigators to ensure the accuracy of the entered data. Data analysis was performed with the Statistical Packages for Social Sciences (SPSS), Version 24 (IBM, Armonk, New York, USA). Independent sample t and Chi-squared tests were used to compare the scores of skill competency and knowledge of both groups of students. Levels of satisfaction for both groups were calculated and presented as frequency, percentage and mean scores, but they were not compared as the two questionnaires were different.

Ethical approval was obtained from the Research and Ethics Committee at the College of Nursing (CON/GP/2020/04) and permission was received from the Fundamentals of Nursing Laboratory course coordinators. The procedure was explained to the students in detail and written informed consent was provided by the participants in both groups. Data confidentiality was maintained. Names and identification numbers of the students were coded and the collected data were stored in a locked cabinet. Permission to use the questionnaires was obtained from their respective authors. The interactive educational video on oral medication administration was shared with both groups after the completion of the study period so that both could benefit equally from the interactive educational video.

\section{Results}

A total of 55 nursing students were included in this study. The study participants were enrolled from the College of Nursing's BSN programme and had registered in the Fundamentals of Nursing Laboratory course for the Spring 2020 semester. A total of 34 (61.81\%) students were females and 21 (38.19\%) were males and aged between 19 and 21 years.

The first objective was to compare the knowledge of both groups (control and experimental) regarding appropriate oral medication administration procedures. Knowledge was assessed using five MCQs developed by the course experts. Scores were assigned as 1 or 2 (poor), 3 or 4 (good) and 5 (excellent). The majority of students $(36,65.45 \%)$ had a good level of knowledge regarding oral medication administration and there was no significant difference between the control and experimental groups $\left(X^{2}[2,55]=2.626 ; P\right.$ $=0.269)$ [Table 1$]$.

Table 1: Comparison of medication administration knowledge scores between the control and experimental groups $(\mathrm{N}=55)$

\begin{tabular}{|c|c|c|c|c|c|}
\hline \multirow[t]{2}{*}{ Knowledge scores* } & \multicolumn{3}{|c|}{ n (\%) } & \multirow[t]{2}{*}{$x^{2}$} & \multirow[t]{2}{*}{$P$ value } \\
\hline & $\begin{array}{l}\text { Experimental group } \\
\qquad(\mathrm{n}=25)\end{array}$ & $\begin{array}{l}\text { Control group } \\
\quad(\mathbf{n}=30)\end{array}$ & $\begin{array}{c}\text { Total } \\
(\mathrm{N}=55)\end{array}$ & & \\
\hline Excellent & $2(8.0)$ & $0(0.0)$ & $2(3.64)$ & 2.626 & 0.269 \\
\hline Good & $15(60.0)$ & $21(70.0)$ & $36(65.45)$ & & \\
\hline Poor & $8(32.0)$ & $9(30.0)$ & $17(30.91)$ & & \\
\hline
\end{tabular}

"A score of 5 was considered excellent, 3 and 4 were considered good and 1 and 2 were considered poor 
Table 2: Competency scores of oral medication administration skill for the control and experimental groups $(\mathrm{N}=55)$

\begin{tabular}{|c|c|c|c|c|c|}
\hline \multirow[t]{2}{*}{ Skill performance* } & \multicolumn{3}{|c|}{ n (\%) } & \multirow[t]{2}{*}{$x^{2}$} & \multirow[t]{2}{*}{$P$ value } \\
\hline & $\begin{array}{l}\text { Experimental group } \\
\qquad(\mathrm{n}=25)\end{array}$ & $\begin{array}{l}\text { Control group } \\
\quad(\mathbf{n}=30)\end{array}$ & $\begin{array}{c}\text { Total } \\
(\mathrm{N}=55)\end{array}$ & & \\
\hline Excellent performance & $10(40)$ & $10(33.33)$ & $20(36.36)$ & 0.262 & 0.609 \\
\hline Good performance & $15(60)$ & $20(66.67)$ & 35 (63.64) & & \\
\hline
\end{tabular}

*A score between 40-80\% was considered a good performance and above $80 \%$ was considered an excellent performance.

Table 3: Control group satisfaction scores with the general demonstration $(\mathrm{n}=30)$

\begin{tabular}{ll}
$\begin{array}{l}\text { General demonstration satisfaction } \\
\text { items* }\end{array}$ & Mean \pm SD \\
\hline Class size is appropriate. & $3.33 \pm 0.994$ \\
The class activities were engaging. & $3.77 \pm 1.073$ \\
The class environment was inviting. & $3.63 \pm 1.066$ \\
The class was fun. & $3.90 \pm 1.213$ \\
$\begin{array}{l}\text { I was bored in the class. } \\
\text { I enjoyed going to class. }\end{array}$ & $3.50 \pm 1.106$ \\
$\begin{array}{l}\text { I felt comfortable to voice my opinion } \\
\text { during class. }\end{array}$ & $3.73 \pm 1.143$ \\
$\begin{array}{l}\text { I learned from my peer experiences. } \\
\text { I felt my presence was valued in the class. }\end{array}$ & $3.73 \pm 1.081$ \\
$\begin{array}{l}\text { I felt comfortable approaching the } \\
\text { instructor. }\end{array}$ & $3.67 \pm 0.994$ \\
$\begin{array}{l}\text { The instructor encourages class discussions. } \\
\text { I recommend this teaching method to be }\end{array}$ & $4.13 \pm 1.129$ \\
continued for future. & $3.97 \pm 0.765$ \\
$\begin{array}{l}\text { SD = standard deviation. } \\
\text { "scores based on a 5-point Likert scale. }\end{array}$ &
\end{tabular}

The second objective was to compare the skill competency scores of both groups. Skill competency of the participants in performing oral medication procedure was evaluated by two evaluators using a standardised checklist; the average was the final score of the participants. Scores $<40 \%$ were classified as poor performance, $40-80 \%$ as good performance and $>80 \%$ as excellent performance. The majority of students (n $=35,63.64 \%$ ) displayed good performance scores and none were in the poor performance category. There was no significant difference in the skill performance of both groups $\left(X^{2}[1,55]=0.262 ; P=0.609\right)$ [Table 2]

The third objective was to describe the satisfaction level of the students who learned the procedure by the traditional demonstration method (control group). These students were asked to rate their satisfaction with the general demonstration using a five-point Likert scale anchored by 1 (strongly disagree) and 5
Table 4: Experimental group satisfaction scores with the interactive educational video $(\mathrm{n}=25)$

\begin{tabular}{|c|c|}
\hline $\begin{array}{l}\text { Video satisfaction scores of the } \\
\text { experimental group* }\end{array}$ & Mean \pm SD \\
\hline $\begin{array}{l}\text { The video recordings are very important } \\
\text { in understanding the procedure steps. }\end{array}$ & $2.56 \pm 0.651$ \\
\hline $\begin{array}{l}\text { The use of video was important for } \\
\text { continuing interest in the course. }\end{array}$ & $2.20 \pm 0.577$ \\
\hline $\begin{array}{l}\text { Watching the videos prior to the } \\
\text { laboratory session was beneficial in my } \\
\text { preparation for the laboratory session. }\end{array}$ & $2.40 \pm 0.764$ \\
\hline $\begin{array}{l}\text { The 'important points' stated for skills in } \\
\text { the videos are very valuable. }\end{array}$ & $2.32 \pm 0.690$ \\
\hline $\begin{array}{l}\text { I would like there to be videos for all of } \\
\text { the skills. }\end{array}$ & $2.28 \pm 0.792$ \\
\hline $\begin{array}{l}\text { The videos decreased my stress during } \\
\text { the laboratory. }\end{array}$ & $2.04 \pm 0.676$ \\
\hline $\begin{array}{l}\text { The sounds/images of the videos were } \\
\text { very clear. }\end{array}$ & $2.08 \pm 0.812$ \\
\hline $\begin{array}{l}\text { The explanation of the skills steps in } \\
\text { the videos helped me to pronounce the } \\
\text { terms correctly. }\end{array}$ & $2.36 \pm 0.700$ \\
\hline $\begin{array}{l}\text { The procedure steps in the videos were } \\
\text { very clear. }\end{array}$ & $2.64 \pm 0.638$ \\
\hline $\begin{array}{l}\text { I can control the video easily (to watch } \\
\text { the steps again, to advance and to } \\
\text { rewind). }\end{array}$ & $2.48 \pm 0.823$ \\
\hline $\begin{array}{l}\text { The use of different learning materials } \\
\text { (video) increased my learning. }\end{array}$ & $2.48 \pm 0.586$ \\
\hline $\begin{array}{l}\text { I prefer educational video to traditional } \\
\text { laboratory explanation. }\end{array}$ & $2.20 \pm 0.707$ \\
\hline $\begin{array}{l}\text { I feel more responsibility in learning } \\
\text { through video than through the } \\
\text { traditional way. }\end{array}$ & $2.24 \pm 0.663$ \\
\hline $\begin{array}{l}\text { The video showing provided for me to } \\
\text { access knowledge more rapidly. }\end{array}$ & $2.40 \pm 0.645$ \\
\hline $\begin{array}{l}\text { The video showing advanced my } \\
\text { learning. }\end{array}$ & $2.56 \pm 0.651$ \\
\hline $\begin{array}{l}\text { I was entertained while learning with the } \\
\text { video showing. }\end{array}$ & $2.44 \pm 0.712$ \\
\hline $\begin{array}{l}\text { Narrating explanation for the skills } \\
\text { steps during the video helped me to } \\
\text { understand the procedure. }\end{array}$ & $2.44 \pm 0.651$ \\
\hline
\end{tabular}




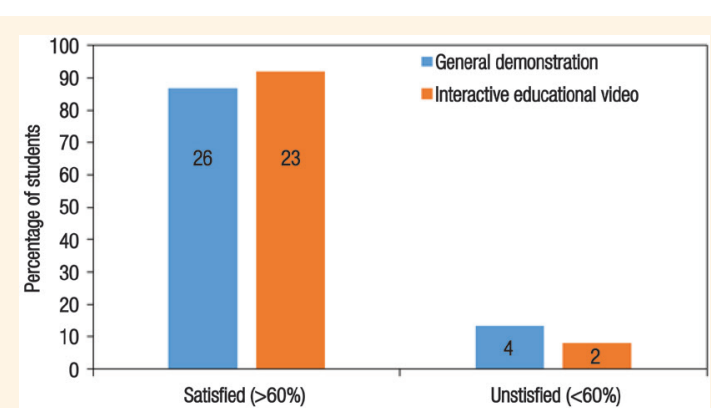

Figure 1: Students' satisfaction with the skill general demonstration and the interactive educational video approach.

(strongly agree). The students in the control group were satisfied with the demonstration, with mean scores $>3.5$ for all items and 26 (86.70\%) students in the control group considered traditional demonstration as highly satisfactory [Table 3 and Figure 1].

The fourth objective was to describe the satisfaction level of the students who learned the procedure by the interactive educational video (experimental group). These participants rated the videos using a three-point Likert scale. A mean score of 2.5 and above on the items indicated a high level of satisfaction. The video recordings were reported to be very important in understanding the procedure steps (mean $=2.56$ ). The procedure steps in the videos were very clear (mean $=2.64)$, with students agreeing that 'I can control the video easily (to watch the steps again, to advance, to rewind' (mean $=2.48$ ), 'The use of different learning materials (video) increased my learning' (mean $=2.48$ ) and 'The video showing advanced my learning' $($ mean $=2.56)$ [Table 4]. Furthermore, 23 (92\%) students were highly satisfied with the interactive educational video learning strategy [Figure 1].

\section{Discussion}

The advanced technologies accessible to the new generation of nursing students have created opportunities for nursing educators to use interactive educational video recording as a teaching approach to help students learn and practice nursing skills. The current study aimed to assess the effectiveness of using an interactive educational video over traditional demonstration on students' knowledge gain, clinical skills competency and levels of satisfaction. The results revealed no statistical differences between the knowledge, skill competency scores and satisfaction levels of the study groups, indicating that both teaching approaches have similar student outcomes. This is similar to the findings of the studies on video learning for basic nursing skills among Turkish nursing students as well as on teaching the subcutaneous injection administration procedure using face-to-face demonstration versus computer-assisted learning among Turkish nursing students. ${ }^{24,27}$ Vicdan used Instagram (Meta Platforms, Menlo Park, California, USA) to teach intramuscular injection administration to students enrolled in the Fundamentals of Nursing course. $^{4}$ The results showed no statistical difference of knowledge and competency scores between groups. In all these studies, the results indicate that the outcomes of interactive video learning for teaching nursing skills were as good as the traditional face-toface demonstration method. This is a positive sign, suggesting interactive videos may appropriately be integrated into fundamental nursing skills courses. Indeed, another study revealed that educational video learning was better than traditional general demonstration for learning a urinary catheterisation procedure, with a significant improvement in knowledge and competency scores. ${ }^{14}$

Nursing students in the experimental group were satisfied with all aspects of the experience and indicated higher satisfaction levels with several items, including clarity of the procedure's steps, feasibility to watch at their own pace or many times and the enhancement of their interest to learn through advanced technology. These findings are similar to those of studies carried out among nursing students learning web-based medication application skills. ${ }^{16,28,29}$ Another study conducted among students on antenatal examination revealed significantly higher levels of knowledge and competency scores in groups of students subjected to online videos, suggesting that this approach may be appropriately implemented in other courses. ${ }^{30}$

Nevertheless, the control group students who witnessed the traditional general demonstration also exhibited high satisfaction levels. Since they were second-year nursing students and it was their first experience of learning skills, they may have appreciated face-to-face student-faculty interactions and valued the opportunity to ask questions in the classroom. While students preferred the social presence of the faculty during the demonstration of skills, they were satisfied with the encouragement they received in their discussion at the end of the sessions. This may encourage faculty to introduce a flipped classroom approach among Fundamentals of Nursing course students when learning basic skills. This approach may improve their critical thinking, clinical judgement, learning motivation, communication and teamwork skills. ${ }^{13}$ Moreover, in this study, the experimental group had a six-hour laboratory session each day 
for two days, while the control group had eighthour laboratory sessions. As the nursing students in the experimental group watched the interactive educational videos at home, a total of four hours was gained and reduced from the face-to-face laboratory session. Thus, interactive educational videos could be used to save time in the classroom, which can then be utilised to build on the previously acquired knowledge.

This study is not without its limitations. First, the results cannot be generalised, as the study was conducted at a single institution in Oman and on a single nursing fundamental skill. Furthermore, research should be done among different courses in the BSN programme with larger sample sizes and including more than one institution. A more rigorous research design, such as a randomised controlled trial, is recommended to control the effect of confounding variables on the findings of future studies.

\section{Conclusion}

This study shows that an interactive educational video approach can be easily adopted for undergraduate nursing students learning basic nursing skills, as it is as effective as traditional methods in achieving student learning outcomes. In future studies, a combination of technology (using interactive educational videos to demonstrate nursing skills) and face-to-face, handson demonstration should be investigated and used to determine if it yields a better outcome. However, this study shows that when face-to-face meetings are not possible (e.g. during lockdowns due to the COVID-19 pandemic), a switch to online interactive educational videos could be made without fear of falling short of necessary programme outcomes.

\section{AUTHORS' CONTRIBUTION}

JN designed the study and supervised the project. ZSS, $\mathrm{SSH}, \mathrm{DKH}, \mathrm{ANK}$ and IMM conducted the experiment and collected the data. JN and MAJ analysed and interpreted the results. MAJ designed and prepared the tables and figures. JN and MAJ drafted the manuscript. All the authors approved the final version of the manuscript.

\section{CONFLICT OF INTEREST}

The authors declare no conflicts of interest.

\section{FUNDING}

No funding was received for this study.

\section{References}

1. Bloomfield J, Roberts J, While A. The effect of computerassisted learning versus conventional teaching methods on the acquisition and retention of handwashing theory and skills in pre-qualification nursing students: A randomised controlled trial. Int J Nurs Stud 2010; 47:287-94. https://doi.org/10.1016/j. ijnurstu.2009.08.003.

2. Forehand JW, Miller B, Carter H. Integrating mobile devices into the nursing classroom. Teach Learn Nurs 2017; 12:50-2. https://doi.org/10.1016/j.teln.2016.09.008.

3. O'Connor S, Andrews T. Smartphones and mobile applications (apps) in clinical nursing education: A student perspective. Nurse Educ Today 2018; 69:172-8. https://doi.org/10.1016/j. nedt.2018.07.013

4. Vicdan AK. Assessment of the effect of mobile-assisted education regarding intramuscular injection by using the Instagram app. Nurs Pract Today 2020; 7:61-71. https://doi.org/10.18502/npt. v7i1.2302.

5. Montenery SM, Walker M, Sorensen E, Thompson R, Kirklin D, White R, et al. Millennial generation student nurses' perceptions of the impact of multiple technologies on learning. Nurs Educ Perspect 2013; 34:405-9. https://doi.org/10.5480/10-451.

6. Risling T. Educating the nurses of 2025: Technology trends of the next decade. Nurse Educ Pract 2017; 22:89-92. https://doi. org/10.1016/j.nepr.2016.12.007.

7. Terry VR, Terry PC, Moloney C, Bowtell L. Face-to-face instruction combined with online resources improves retention of clinical skills among undergraduate nursing students. Nurse Educ Today 2018;61:15-19. https://doi.org/10.1016/j.nedt.2017.1 0.014

8. NLN. A vision for the changing faculty role: Preparing students for the technological world of health care. Nurs Educ Prespect $2015 ; 36: 134$.

9. Mayer R. Ten research-based principles for designing multimedia instruction. From: https://www.learntechlib.org/primar y/p/180549/ Accessed: Nov 2021.

10. Branigan C. Video goes to school. Part I: Whether watching or recording, students find video engaging. 2005. From: http://web.archive.org/web/20091207210935/http:// www.eschoolnews.com/news / top-news/index. $c f m ? i=36294 \&$ CFID $=30198904 \&$ CFTOKEN $=36755434$ Accessed: Nov 2021

11. Kosterelioglu I. Student views on learning environments enriched by video clips. Univers J Educ Res 2016; 4:359-69. https://doi.org/10.13189/UJER.2016.040207.

12. Wijnker W, Bakker A, van Gog T, Drijvers P. Educational videos from a film theory perspective: Relating teacher aims to video characteristics. Br J Educ Technol 2019; 50:3175-97. https:// doi.org/10.1111/bjet.12725.

13. Goedhart NS, Blignaut-van Westrhenen N, Moser C, Zweekhorst MBM. The flipped classroom: Supporting a diverse group of students in their learning. Learning Environ Res 2019; 22:297-310. https://doi.org/10.1007/s10984-019-09281-2.

14. Chuang Y-H, Lai F-C, Chang C-C, Wan H-T. Effects of a skill demonstration video delivered by smartphone on facilitating nursing students' skill competencies and self-confidence: A randomized controlled trial study. Nurse Educ Today 2018; 66:63-8. https://doi.org/10.1016/j.nedt.2018.03.027.

15. Zayim N, Ozel D. Factors affecting nursing students' readiness and perceptions toward the use of mobile technologies for learning. Comput Inform Nurs 2015; 33:456-64. https://doi. org/10.1097/CIN.0000000000000172.

16. Lee N-J, Chae S-M, Kim H, Lee J-H, Min HJ, Park D-E. Mobilebased video learning outcomes in clinical nursing skill education: A randomized controlled trial. Comput Inform Nurs 2016; 34:8-16. https://doi.org/10.1097/CIN.0000000000000183. 
17. Alkhalaileh M, Hasan A, Al-Rawajfah O. Evaluate the effectiveness of clinical simulation and instructional video training on the nursing students' knowledge about cardio-pulmonary resuscitation: Comparative study. Am J Educ Res 2017; 5:172-8.

18. Devi B, Khandelwal B, Das M. Comparison of the effectiveness of video-assisted teaching program and traditional demonstration on nursing students learning skills of performing obstetrical palpation. Iran J Nurs Midwifery Res 2019; 24:118. https://doi. org/10.4103/ijnmr.IJNMR_35_18.

19. Asensi-Vicente J, Ismael JR, Vizcaya-Moreno MF. Medication errors involving nursing students: A systematic review. Nurse Educ 2018; 43: E1-5. https://doi.org/10.1097/NNE.0000000000 000481

20. Joel MH, Ashipala DO, Kamenye E. Interactive video technology as a mode of teaching: A qualitative analysis of nursing students' experiences at a higher education institution in Namibia. Int High Educ 2021; 10:83-91. https://doi.org//10.5430/ijhe.v10n2p83.

21. Gagné RM. Conditions of learning and theory of instruction. Holt, Rinehart and Winston: USA. 1985.

22. Thorpe R. Digital technology in classrooms: Video in teaching and learning. NHK Broadcasting Studies 2008; 6:2145.

23. Kozier BJ, Erb G, Berman AT, Snyder S, Frandsen G, Buck M, et al. Fundamentals of Canadian nursing: Concepts, process, and practice, 4th ed. Pearson Canada: Canada. 2018.
24. Arslan GG, Ozden D, Goktuna G, Ayik C. A study on the satisfaction of students for the time spent watching video-based learning during their basic nursing skills' training. Int J Caring Sci 2018; 11:427-36.

25. Coffey M, Gibbs G. The evaluation of the Student Evaluation of Educational Quality Questionnaire (SEEQ) in UK higher education. Assess Eval High Educ 2001; 26:89-93. https://doi. org/10.1080/02602930020022318.

26. Centra JA. Reflective faculty evaluation: Enhancing teaching and determining faculty effectiveness. The Jossey-Bass Higher and Adult Education Series, 1st ed. New York, USA: Wiley, 1993.

27. Vicdan AK. Teaching subcutaneous injection using face-to-face and computer-assisted training. Int J Caring Sci 2018; 11:344-52.

28. Bahar A. Effects of web based instructional video supported education on basic skills training. New J Med 2015; 32:141-7.

29. Pinar G, Abay H, Akalin A. The effect of scenario-based simulation training technology on knowledge and skills of maternity nursing students in Turkey. Int J Dev Res 2016; 6:8096-101.

30. Scaria T, Valsaraj P, Pias M. The effectiveness of video teaching over lecture cum demonstration in improving knowledge and skill, of nursing students on antenatal examination. Int J Nurs Educ 2013; 5:228-30. 